\title{
Programação de computadores para melhoria da aprendizagem
}

Recebido em 21.12.2013. Aprovado em 28.12. 2013 Avaliado pelo sistema double blind review

\author{
Adriana Moralles \\ drimoralles@gmail.com \\ Centro Educacional SESI No 108 - São Carlos -SP - Brasil.
}

\section{Resumo}

Estamos vivendo uma realidade onde a tecnologia invadiu todos os ambientes de trabalho, escolas, casas... O que temos hoje em termos de tecnologia , será obsoleto daqui 2, 3 anos, tamanha é a rapidez da evolução tecnológica. As opções de trabalho vão sofrer uma grande transformação. Segundo pesquisas, ainda não conhecemos a maioria das ocupações profissionais que existirão daqui a 10 anos.

Seguindo essa lógica e baseados nos resultados da escola em avaliações externas e internas, percebemos uma fragilidade dos alunos em relação ao desenvolvimento do raciocínio lógico e na interpretação de textos/dados. Os resultados das avaliações como SARESP e ENEM, trouxeram a consciência da necessidade de aprofundar conhecimentos nas áreas da matemática(resolução de problemas) e português (interpretação de textos/dados).

Pensamos em aliar a tecnologia, através da programação em computadores, para a melhoria da aprendizagem dos alunos, visando o desenvolvimento do raciocínio lógico e favorecendo também a interpretação de textos/dados. O Plano de empreendimento escolhido "Programação de computadores para melhoria da aprendizagem", foi pensado a partir da necessidade de melhorar o raciocínio lógico e a criatividade dos alunos, através de situações-problema reais que necessitam de soluções.

Contamos com uma equipe de professores dinâmicos, com disposição para aprender e abertos à mudanças que favorecem a aprendizagem dos alunos.

Para a realização do Plano de Empreendimento, o valor solicitado ao edital será de $\mathrm{R} \$ 23.891,95$ destinados a compra de computadores, softwares, contratação de professor especializado em programação de computadores, treinamento de professores, despesas com material de consumo e serviços, despesas correntes e manutenção.

Esperamos contar com o apoio financeiro necessário para o desenvolvimento desse Plano de Empreendimento que tem como objetivo criar uma geração de pessoas confiantes e que possam controlar e manipular o mundo digital, em vez de apenas consumir passivamente o conteúdo.

Nos capítulos seguintes poderemos conhecer melhor o Plano de Empreendimento que já vislumbra os frutos desse trabalho promissor.

Acreditamos que a educação é fundamental para melhorar e desenvolver as pessoas em busca de um mundo melhor.

Palavras-chaves: Educação. Tecnologias de ensino. Programação. Plano de empreendimento. 


\section{Contexto da escola}

A escola encontra-se localizada em bairro novo na cidade de São Carlos e apresenta no entorno da escola, comércio (padaria, sacolão, loja de material de construção, papelaria, bares, supermercado, comércio em geral), residências (casas), outras escolas (municipal e estadual) e igreja.

A escola atende aos ensinos fundamental e médio regular nos períodos matutino e vespertino, com educação em tempo integral aos alunos do $1^{\circ}$ ao $9^{\circ}$ ano, ampliando de forma gradativa, sendo que no ano de 2014 estaremos atendendo do $1^{\circ}$ ao $8^{\circ}$ ano integral e no ano de 2015 estaremos atendendo todo 0 ensino fundamental do $1^{\circ}$ ao $9^{\circ}$ ano em tempo integral,oferece também ensino à distância no período noturno( fundamental e médio) e Programa de Alfabetização de Adultos.

A educação integral em tempo integral possui currículo diferenciado, pois além dos componentes curriculares da base nacional comum e a parte diversificada, que tem como objetivo enriquecer e complementar a base nacional comum (Resolução CNE/CEB nº 4 de 13/07/2010, Art. 14 e 15) e complementado pelas vivências de enriquecimento curricular.

As vivências de enriquecimento curricular estão contempladas na carga horária e compõem a parte diversificada, são elas: orientação de estudos; esporte escolar, vivências artísticas, vivência em ciência e tecnologia incluindo o trabalho com o lego e robótica e empreendedorismo.

A escola possui prédio novo e moderno, foi inaugurada em 26 de junho de 2009, atendendo ensinos fundamental e médio. A escola conta com as seguintes dependências:

$>12$ Salas de Aula;

01 Sala Multidisciplinar;

> 01 Sala de Ciência e Tecnologia (Utilizada pela equipe de Supervisão Técnica educacional)

> 01 Biblioteca;

> 01 Laboratório de Ciência e Tecnologia;

> 02 Áreas de Convivência;

> 01 Quadra Poliesportiva coberta;

> 01 Refeitório;

> 04 Banheiros para Alunos (Feminino);

$>4$ Banheiros para Alunos (Masculino);

> 02 Banheiros para Alunos portadores de necessidades especiais (Feminino);

$>02$ Banheiros para Alunos portadores de necessidades especiais (Masculino);

$>$ Diversas áreas livres, descobertas, com piso em bloquetes;

> 01 Secretaria;

$>01$ Sala de Arquivo;

> 01 Almoxarifado;

> 01 Cozinha com despensa acoplada;

> 01 Sala de Professores;

> 01 Sala de Administração;

> 01 Sala para Atendimento aos pais;

> 01 Sala de Coordenação Pedagógica;

> 01 Depósito de Materiais de higiene e limpeza;

> 01 Vestiário de funcionários com banheiro (Feminino);

> 01 Vestiário de funcionários com banheiro (Masculino); 


\section{Programação de computadores para melhoria da aprendizagem}

D 01 Banheiro de Professores (Feminino);

> 01 Banheiro de Professores (Masculino);

> 01 Banheiro para Funcionários (Feminino);01 Banheiro para Funcionários (Masculino).

Inseridos na Proposta Pedagógica, Programas da Rede Escolar SESI-SP e Plano Estratégico da Rede SESI$\mathrm{SP}$, nosso esforço continuará sendo para uma oferta de educação de qualidade com foco no trabalhador da indústria e sua família.

Nossa escola, em reunião para a construção da Proposta Pedagógica, com a participação de professores e funcionários, construiu a missão, a visão e os valores que julgamos serem importantes para o trabalho com a formação de indivíduos.

Missão: Formar cidadãos críticos, autônomos e transformadores de seu meio, promovendo uma educação de qualidade.

Visão: Ser uma escola de excelência, formadora de alunos que valorizem o conhecimento, a arte, a ética e a responsabilidade.

Valores: Comprometimento e responsabilidade com a equipe e com a Proposta Pedagógica da escola; comprometimento de cada colaborador, incluindo integridade, dignidade, ética e lealdade com os combinados da equipe; valorização do ser humano e da harmonia nas relações sociais; respeito ao meio ambiente; comprometimento social.

\section{Breve histórico da escola}

O Centro Educacional SESI № 108, iniciou suas atividades no ano de 1962, com a implantação do Salário Educação. A escola era patrocinada pelo Frigorífico São Carlos do Pinhal que construiu duas salas de aula em terreno próprio e cedeu gratuitamente ao SESI. Este prédio ficava situado à Av. Prof. Luiz Augusto de Oliveira, 267-Bairro Monjolinho. Funcionavam nessa época, classes de Ensino Supletivo $\left(1^{\mathrm{a}}\right.$ a $4^{\mathrm{a}}$ séries) nos períodos da manhã, tarde e noite.

Com a implantação da Lei 5.692, houve a criação de uma classe de $5^{\text {a }}$ série.

Em 1985, o CE foi ampliado com a expansão das classes de $5^{\mathrm{a}}$ a $8^{\mathrm{a}}$ séries.

As salas de $1^{\mathrm{a}}$ a $4^{\mathrm{a}}$ séries funcionavam de manhã e a tarde, e as de $5^{\mathrm{a}}$ a $8^{\mathrm{a}}$ séries no vespertino.

Com a construção de mais duas salas de aula em 1997, passou a funcionar em dois períodos, com seis salas de aula e uma oficina.

Em agosto de 2000, foi implantado no CE o Telecurso 2000, com duas classes, uma do Fundamental e uma com o Programa de Alfabetização Intensiva, ambas a noite.

Em agosto de 2002, foi implantada uma classe do Telecurso 2000, Ensino Médio.

Em outubro de 2007, a Prefeitura Municipal de São Carlos, doou um terreno ao SESI, para a construção de uma nova escola.

A nova escola foi inaugurada em 26 de junho de 2009 ,atendendo em prédio novo e moderno.

\section{Perfil dos alunos e professores}

Os alunos são na sua maioria beneficiários (67\%). Do total de alunos beneficiários e não beneficiários temos $33 \%$ isentos. O perfil da clientela da nossa escola é considerado bom, pois a maioria dos pais está comprometida com a vida escolar de seus filhos; porém, é percebido que o acompanhamento da família vai diminuindo à medida que os alunos vão crescendo. A clientela é diversificada, vinda de bairros distintos e de 
diversas classes sociais.

Os alunos na sua maioria, apresentam facilidade nas relações interpessoais com colegas, funcionários e professores.

Quanto a equipe docente, temos 27 professores na escola, são na sua maioria(12 professores) jovens entre 20-30 anos, 8 professores estão entre 40 e 50 anos, 6 professores estão entre 30 e 40 anos e apensa 1 professor com mais de 50 anos.

Do total de professores, temos 8 com mestrado,e muitos possuem especialização.

A maioria dos professores é comprometida e aberta a implementações, são críticos e bem humorados, com boa relação interpessoal entre colegas, funcionários e alunos.

\section{Características mais marcantes do local onde a escola se insere}

O bairro é novo e um pouco afastado do centro da cidade. Possui toda a infra-estrutura de saneamento básico, possui comércio e residências na sua maioria de nível médio.

A cidade possui muitas indústrias e duas universidades USP e Federal, além de outra faculdade particular (UNICEP). A cidade é considerada a capital da tecnologia. A escola SENAI de São Carlos oferece cursos técnicos de grande procura, e nossos alunos( maioria) fazem SENAI concomitante com o SESI a partir do $2^{\circ}$ ano do ensino médio, tendo a oportunidade de mais uma formação técnica de qualidade, além do ensino médio.

\section{Identificação do problema ou da oportunidade}

A partir da realidade da nossa escola em relação aos resultados atingidos no SARESP, entendemos que há necessidade de se trabalhar de forma incisiva com o desenvolvimento do raciocínio lógico, incluindo interpretação de dados existentes e desenvolvimento de criatividade.

Entendemos que a interpretação está ligada também ao raciocínio lógico e a leitura que se faz de todos os dados existentes e a busca de maneiras para resolver o problema, trabalhando com eliminação de hipóteses não aceitáveis.

Analisando os resultados e fazendo a leitura dos Clusters, percebemos a fragilidade em Matemática.

Resultados do SARESP 2011 e 2012 da escola:

No ano de 2011 tivemos como resultado do SARESP :

$3^{\circ}$ ano - LP: 92,8 e MA: 94,8;

$5^{\circ}$ ano - LP: 244,9 e MA: 268,5;

$6^{\mathrm{a}}$ série - LP: 255,2, MA: 266,5, GEO: 272,5,HI: 280,5;

$8^{a}$ série - LP: 276,2, MA: 288,9, GEO: 297 e HI: 293,6;

$3^{0}$ ano ensino médio - LP: 306,7, MA: 312,7, GEO: 306,8 e HI: 299,2.

Ficamos classificados com o Cluster 2: Mau Desempenho no $9^{\circ}$ Ano, a saber:

$\checkmark$ Composto por $23 \%$ das Escolas SESI-SP e $28 \%$ das matrículas efetivas;

$\checkmark$ Desempenho mediano abaixo dos demais clusters (com exceção do cluster 4, grupo crítico) no $5^{\circ}$ ano;

$\checkmark$ Baixos índices de desempenho em matemática e língua portuguesa para os alunos do $9^{\circ}$ ano;

$\checkmark$ Comparado aos demais clusters (com exceção do cluster 4), possui altos percentuais de alunos 


\section{Programação de computadores para melhoria da aprendizagem}

abaixo do nível adequado em matemática no $5^{\circ}$ ano: $75 \%$ das unidades possuem no mínimo $20 \%$ dos alunos com desempenho abaixo do nível adequado;

$\checkmark$ Altos percentuais de alunos abaixo do nível adequado em matemática e língua portuguesa no $9^{\circ}$ ano:

- Mais de $50 \%$ das escolas possuem pelo menos $60 \%$ dos alunos abaixo do nível adequado em matemática;

- Mais de $75 \%$ das escolas possuem pelo menos $40 \%$ dos alunos abaixo do nível adequado em língua portuguesa.

No ano de 2012 tivemos como resultado do SARESP :

$5^{\circ}$ ano - LP: 230,3 e MA: 246,5 ;

$6^{a}$ série - LP: 247,6 ; MA: 267,2; CIÊNCIAS : 277,2

$8^{\mathrm{a}}$ série - LP: 276,8; MA: 299,9; CIÊNCIAS : 298,0

$3^{\circ}$ ano ensino médio - LP: 298,3; MA: 320,4;CIÊNCIAS DA NATUREZA: 321,2.

Ficamos classificados no Ensino Médio com Cluster 1:

Grupo Crítico A

-Composto por $40 \%$ das Escolas SESI SP e 36\% das matrículas efetivas;

-Baixos índices de desempenho em português e matemática:

- 25\% das escolas do cluster possuem níveis de proficiência básico em língua portuguesa. $\mathrm{E}$ as demais estão como adequado, porém muito próximas do básico;

- 100\% das escolas possuem níveis de proficiência básico em matemática.

- Maiores percentuais de desempenho dos alunos abaixo do nível adequado em matemática: $75 \%$ das Escolas SESI-SP deste cluster possuem pelo menos $70 \%$ dos alunos com aprendizagem abaixo do adequado. Mas, comparando 2011 com 2012, quase 50\% das escolas melhoraram o seu desempenho;

- Altos percentuais de aprendizagem abaixo do adequado em português.

Ficamos classificados no Ensino Fundamental com Cluster 1:

No Geral, Bom Desempenho

- Composto por $11 \%$ das Escolas SESI-SP e $9 \%$ das matrículas efetivas;

- Bons índices de desempenho em matemática e língua portuguesa para todos os anos avaliados do ensino fundamental. Atenção ao $7^{\circ}$ ano, pois nota-se desempenho abaixo do cluster 3 e similar aos demais clusters (com exceção do cluster 4, grupo crítico);

- Menores percentuais de alunos abaixo do nível adequado, com exceção do $7^{\circ}$ ano;

-Maiores índices de evoluções no nível de proficiência média em língua portuguesa e

matemática, para $03^{\circ}, 5^{\circ}$ e $9^{\circ}$ ano de 2011 para 2012;

- Poucos componentes avaliados com mais de $50 \%$ dos alunos classificados abaixo do adequado: $75 \%$ das escolas deste cluster possuem no máximo duas. 


\section{Adriana Moralles}

\begin{tabular}{|c|c|c|c|c|}
\hline $3^{\circ}$ ano fundamental & Nível de proficiência \\
\hline Disciplinas: & Insuficiente & Básico & Pleno & Avançado \\
\hline Matemática & 2 & 2 & 11 & 17 \\
\hline Língua Portuguesa & 0 & 1 & 20 & 11 \\
\hline
\end{tabular}

\begin{tabular}{|l|l|l|l|l|}
\hline $\mathbf{5}^{\circ}$ ano fundamental & Nível de proficiência \\
\hline Disciplinas: & Abaixo do básico & Básico & Adequado & Avançado \\
\hline Matemática & 2 & 5 & 18 & 5 \\
\hline Língua Portuguesa & 1 & 7 & 16 & 8 \\
\hline
\end{tabular}

\begin{tabular}{|l|l|l|l|l|}
\hline \multicolumn{5}{|l}{ Nono fundamental } \\
\hline Disciplinas: & Abaixo do básico & Básico & Adequado & Avançado \\
\hline Matemática & 2 & 5 & 18 & 5 \\
\hline Língua Portuguesa & 1 & 7 & 16 & 8 \\
\hline
\end{tabular}

\begin{tabular}{|l|l|l|l|l|}
\hline $7^{0}$ ano fundamental & Nível de proficiência & Avançado \\
\hline Disciplinas: & Abaixo do Básico & Básico & Adequado & 6 \\
\hline Matemática & & 10 & 13 & 5 \\
\hline Língua Portuguesa & & 7 & 17 & \\
\hline
\end{tabular}

\begin{tabular}{|c|c|c|c|c|}
\hline $9^{\circ}$ ano fundamental & & I de proficiênci & & \\
\hline Disciplinas: & Abaixo do básico & Básico & Adequado & Avançado \\
\hline Matemática & 2 & 9 & 19 & 2 \\
\hline Língua Portuguesa & & 14 & 16 & 2 \\
\hline $3^{\circ}$ ano $\mathrm{A}$ médio & & Nível de & cia & \\
\hline Disciplinas: & Abaixo do Básico & Básico & Adequado & Avançado \\
\hline Matemática & 6 & 16 & 9 & 0 \\
\hline Língua Portuguesa & 7 & 7 & 15 & 2 \\
\hline
\end{tabular}

\begin{tabular}{|l|l|l|l|l|}
\hline \multicolumn{5}{|l|}{$3^{\circ}$ ano Nível de proficiência } \\
\hline Disciplinas: & Abaixo do Básico & Básico & Adequado & Avançado \\
\hline Matemática & 3 & 3 & 5 & 1 \\
\hline Língua Portuguesa & 1 & 4 & 7 & 0 \\
\hline
\end{tabular}

Desempenho no SARESP 2012 


\section{Programação de computadores para melhoria da aprendizagem}

De acordo com os resultados do SARESP 2011 e 2012 da escola, levantamos algumas necessidades para melhorar a aprendizagem dos alunos.

Percebe-se a necessidade de se desenvolver o raciocínio lógico dos alunos, uma vez que o resultado de matemática no SARESP aponta que a maioria dos nossos alunos do ensino médio se encontra no nível básico/ abaixo do básico em matemática. De um modo geral, no ensino fundamental também percebemos uma dificuldade maior em matemática, a partir dos indicadores do SARESP acima.

O Plano de empreendimento proposto inclui o trabalho com parceria do Analista de Suporte em Informática no laboratório de informática, com o desenvolvimento de programação de computadores a partir do $1^{\circ}$ ano do ensino fundamental até $03^{\circ}$ ano do ensino médio.

Os alunos terão a oportunidade de desenvolverem programas de computadores com os professores de sala (diferentes áreas de conhecimento) em parceria com o Analista de Suporte de Informática que dará suporte quanto aos softwares que poderão ser utilizados na proposta de programação.

Programar é uma atividade que envolve a criatividade, requer raciocínio lógico, reflexão e pesquisa, inibindo a memorização e reprodução de informações, envolve o aluno com o problema a ser resolvido. 0 aprendizado baseado na resolução de problemas não é novo e tem sido explorado nos meios tradicionais de ensino.

Entretanto, o computador adiciona uma nova dimensão a essa abordagem: 0 fato de 0 aluno ter de expressar a resolução do problema segundo uma linguagem de programação, obtendo feedback imediato após a execução do programa pelo computador.

Pensamos no trabalho com programação para desenvolver com os alunos, uma vez que a tecnologia digital é uma realidade no cotidiano dos alunos e os problemas quando surgem, precisam de soluções. Visando 0 desenvolvimento de estratégias, criatividade e raciocínio lógico de forma articulada com a realidade dos alunos, contextualizada, entendemos que o trabalho com programação pode melhorar muito a aprendizagem dos alunos.

\section{Caracterização do produto/serviço e/ou processo}

0 projeto proposto diz respeito ao trabalho com programação de computadores a partir do $1^{0}$ ano fundamental, incluindo todos os anos do fundamental e o ensino médio.

O trabalho com programação de computadores já é usado de maneira pontual nas escolas com visão construtivista, sociointeracionista como o SESI por exemplo, trabalhando com a robótica no $6^{\circ}, 7^{\circ}$ anos , $9^{\circ}$ anos e ensino médio(NXT) e nos CATs (arduino).

$\mathrm{Na}$ Inglaterra, de acordo com pesquisas realizadas, já existe investimento nessa linha de trabalho. De acordo com os cientistas de Cambridge, as aulas de informática de hoje não incluem mais a criação de programas ou jogos, focando apenas em softwares do dia a dia. Algumas escolas britânicas, no entanto, iniciaram uma revolução. Professores decidiram ignorar o currículo imposto pelo governo e incentivar as crianças a programar usando softwares gratuitos, como Scratch e Kodu.

Segundo os cientistas de Cambridge, o projeto ainda não atingiu sua principal meta: invadir as escolas e convencer as crianças de que programar é divertido. "O objetivo é criar uma geração de pessoas confiantes e que possam controlar e manipular o mundo digital, em vez de apenas consumir passivamente o conteúdo", afirma Mullins. ${ }^{1}$

Se a escola é universalizada, temos que oferecer uma educação para além dos muros da escola, pois nosso público possui recursos cada vez mais sofisticados e está cada dia mais conectado com as tecnologias da informação, além disso é uma questão de cidadania, temos a obrigação de formar cidadãos críticos e participativos, oferecendo uma educação contextualizada, onde conteúdos estão presentes em toda notícia e em acontecimentos vivenciados no cotidiano.

\footnotetext{
${ }^{1}$ http://g1.globo.com/globo-news/noticia/2012/10/cientistas-criam-computador-para-ensinar-programacao-criancas.html
} 
Sabemos que o papel da escola deve estar articulado às necessidades e valores de cada época. Devemos entender o momento atual, com a intensificação da globalização e perceber a sociedade em constante transformação, onde o que se aprende hoje pode sofrer alterações amanhã. Hoje o alunos precisa ser formado de maneira que a pesquisa seja priorizada, tamanha a importância de desenvolver o sujeito capaz de intervir no seu meio, sabendo que o conhecimento não é estático, está em constante transformação. Não precisamos de sujeitos que repetem o que já existe, mas que criam e recriam a partir do existente.

Queremos desenvolver o sujeito com idéias novas, criativo, flexível, crítico e participativo, desejamos o aluno que não aceite tudo que está posto e defenda e discuta sobre o que acredita.

Também a escola necessita de mudanças e segundo Moran (2007), muitas mudanças são necessárias:

-Um currículo mais integrado, mais próximo do cotidiano, com mais liberdade de percurso, de escolhas, de integração significativa;

-Metodologias mais ativas e focadas em pesquisa e produção, em jogos, na relação prática-teoria-prática;

-Melhor organização do tempo e de espaço, muito mais flexível (educação multiespacial e multitemporal). Uma parte em sala de aula, outra na internet, e outra na cidade, em contato com lugares significativos para aprendizagem e para o trabalho;

-Utilização das mídias possíveis e de forma integrada nos novos nichos educacionais.

Segundo o parecer $07 / 2010$ :

"...a educação é o processo e prática que se concretizam nas relações sociais que
transcendem o espaço e o tempo escolares, portanto, consiste no processo de socialização
da cultura da vida, na qual se constroem, se mantêm e se transformam saberes,
conhecimentos e valores." (parecer 07/2010).

A inovação desse trabalho, fica por conta de introduzir a programação desde os anos iniciais e investir na parceria com todas as disciplinas de forma multidisciplinar, partindo de situações problema.

A oferta seria do $1^{\circ}$ ano do ensino fundamental até $03^{\circ}$ ano do ensino médio, durante as aulas das diferentes disciplinas, havendo parceria do professor que ministra a disciplina com o Analista de Suporte em Informática.

Em todas as disciplinas poderia ser trabalhada a programação, dependeria da ligação com o problema a ser resolvido.

Ao longo prazo teríamos alunos mais pró-ativos, criativos, autônomos, com melhor raciocínio lógico e maior responsabilidade e participação na busca por soluções dos problemas da sociedade. Para os anos iniciais do ensino fundamental, poderíamos usar o software LOGO, uma linguagem simples e que permite criar programações diversas.

Além do software NXT já utilizado nas programações com alunos da escola, poderíamos adquirir outros. Existe um amplo leque de programações que poderemos criar a partir de softwares existentes.

Os professores por sua vez precisam definir qual o trabalho que pretendem desenvolver a partir de uma situação problema. Há necessidade de formação dos professores para um olhar mais voltado para as tecnologias da informação, conhecimento de softwares, bem como suas possibilidades de programação.

\section{Estratégia de implementação}

Realizamos uma análise em relação as forças, fraquezas, oportunidades e ameaças em relação ao projeto apresentado e percebemos que temos forças, na medida em que estamos numa rede SESI de visão futurista, que investe em educação, tecnologia, saúde, esporte, proporcionado qualidade de vida e incentiva e apóia boas práticas .

Vemos a oportunidade de trabalhar com a melhoria da aprendizagem, uma vez que o conhecimento não é estanque e é fomentado na medida em que há estímulos apropriados. Uma cidade considerada da tecnologia com universidades é um ambiente propício para implantar esse projeto.

A fraqueza encontrada, talvez seja a resistência por parte de alguns professores que se sentem ameaçados 


\section{Programação de computadores para melhoria da aprendizagem}

pela invasão da tecnologia e tenham dificuldades em encontrar problemas relacionados a sua disciplina que poderiam ser trabalhados a partir de programação de computador.

Em relação as ameaças, pensamos que a falta de acompanhamento adequado no projeto pode desestimular as pessoas envolvidas, ameaçando o sucesso do projeto.

Temos como objetivo a melhoria na aprendizagem, inicialmente favorecendo o desenvolvimento do raciocínio lógico, a criatividade, e a médio e longo prazo, uma visão mais ampla das situações, com o comprometimento em solucionar problemas, desenvolvendo uma pró-atividade tão necessária para os nossos jovens, evitando uma alienação sobre os problemas sociais.

Existe a necessidade de se utilizar estratégias, como a formação dos professores em relação a ciência e tecnologia, trabalho envolvendo programação de computadores de forma simples e eficaz. Por exemplo, quando o professor do $1^{\circ}$ ano perceber que pode trabalhar com programação de computador para trabalhar com seus alunos um software simples como o LOGO ( cruzadinha,sudoku, jogos...), vai perceber que é muito simples e ao mesmo tempo muito envolvente para o aluno construir sua própria cruzadinha. Essas estratégias de envolvimento do professor, capacitando-o e fazendo acreditar no projeto é um ponto crucial para o sucesso desse empreendimento.

O acompanhamento do projeto se fará no processo, a partir dos resultados dos programas criados pelos alunos e 0 acompanhamento dos resultados nas médias das etapas, bem como o resultado nas participações dos alunos em olimpíadas, avaliações externas, etc.

Para que o projeto se concretize se faz necessário o investimento em softwares, computadores, professores bem formados com conhecimento e envolvimento.

Deverá haver uma pesquisa por parte do Analista de informática e professor, sobre softwares adequados para o trabalho a ser desenvolvido, além de adequação da disciplina com a problemática escolhida.

Os softwares serão adquiridos com a verba de material pedagógico oferecida todo ano às escolas.

Os computadores já existem no laboratório de informática e serão sempre repostos na medida em que houver necessidade.

Veja abaixo a tabela com a definição dos objetivos, matas e estratégias do projeto.

\begin{tabular}{|c|c|c|}
\hline Objetivos & Metas & Estratégias \\
\hline $\begin{array}{l}\text { Temos como objetivo a melhoria na } \\
\text { aprendizagem, inicialmente } \\
\text { favorecendo o desenvolvimento do } \\
\text { raciocínio lógico, a criatividade, e a } \\
\text { médio e longo prazo, uma visão } \\
\text { mais ampla das situações, com o } \\
\text { comprometimento em solucionar } \\
\text { problemas, desenvolvendo uma } \\
\text { pró-atividade tão necessária para } \\
\text { os nossos jovens, evitando uma } \\
\text { alienação sobre os problemas } \\
\text { alheios. }\end{array}$ & $\begin{array}{l}\text { Para a melhoria na aprendizagem, } \\
\text { entendemos que haverá a } \\
\text { necessidade de pelo menos um ano } \\
\text { para começar a ver resultados } \\
\text { melhores ( } 10 \%) \text {, aumentando } \\
\text { gradativamente a melhoria dos } \\
\text { resultados a cada ano. } \\
\text { Para a questão do comprometimento, } \\
\text { ampliação da visão de resolução de } \\
\text { problemas e proatividade } \\
\text { entendemos que precisaremos de } \\
\text { três anos para começar a ver } \\
\text { resultados atitudinais. }\end{array}$ & $\begin{array}{l}\text { Existe a necessidade de se utilizar estratégias, como a } \\
\text { formação dos professores em relação a ciência e } \\
\text { tecnologia, trabalho envolvendo programação de } \\
\text { computadores de forma simples e eficaz. Por exemplo, } \\
\text { quando o professor do } 1^{\circ} \text { ano perceber que pode } \\
\text { trabalhar com programação de computador para } \\
\text { trabalhar com seus alunos um software simples como o } \\
\text { LOGO ( cruzadinha, jogos...), vai perceber que é muito } \\
\text { simples e ao mesmo tempo muito envolvente para o } \\
\text { aluno construir sua própria cruzadinha. Essas } \\
\text { estratégias de envolvimento do professor, capacitando-o } \\
\text { e fazendo acreditar no projeto é um ponto crucial para o } \\
\text { sucesso desse empreendimento. A melhor motivação } \\
\text { para o aluno é ver o brilho nos olhos do professor. }\end{array}$ \\
\hline
\end{tabular}


Plano de Ação para as principais ações definidas nas estratégias:

\begin{tabular}{|c|c|c|}
\hline 0 que vou precisar & Descrição & Como obter \\
\hline $\begin{array}{l}\text { Para que o projeto se } \\
\text { concretize se faz necessário o } \\
\text { investimento em softwares, } \\
\text { computadores e formação de } \\
\text { professores. }\end{array}$ & $\begin{array}{l}\text { Para o trabalho com programação de } \\
\text { computadores é necessário o investimento em } \\
\text { softwares e computadores. A Formação de } \\
\text { professores também é essencial para o } \\
\text { desenvolvimento do projeto. Esses itens são de } \\
\text { extrema importância para o projeto, uma vez que } \\
\text { existe o trabalho com programação de } \\
\text { computadores. }\end{array}$ & $\begin{array}{l}\text { Os softwares serão adquiridos com a verba de } \\
\text { material pedagógico oferecida todo ano ás } \\
\text { escolas. Os computadores já existem no } \\
\text { laboratório de informática e serão sempre } \\
\text { repostos na medida em que houver } \\
\text { necessidade. Para a Formação de professores } \\
\text { precisaremos contratar um especialista em } \\
\text { desenvolvimento de programas. }\end{array}$ \\
\hline
\end{tabular}

\section{Marketing e comunicação}

A escola atual necessita estar mais voltada para o ensino contextualizado com o cotidiano, com a demanda social e intelectual, existe uma dinâmica nos acontecimentos e descobertas que mudam numa velocidade incontrolável, principalmente na área da ciência e tecnologia.

Pesquisas apontam que muitas das profissões que existirão daqui a 10 anos, nem imaginamos quais sejam, tamanha a rapidez na transformação que ocorre na sociedade.

Acompanhar essas mudanças é o desafio da educação atual, não se trata somente de ensinar os jogos com softwares do dia a dia, trata-se de incluir mais a criação de jogos e programas.

"Na Inglaterra, os cientistas de Cambridge criaram um computador do tamanho de um cartão de crédito. Vendido a US\$ 35, ele incentiva crianças a aprender sobre programação e dominar os bastidores do mundo virtual.

Para criar um computador tão barato, os pesquisadores concentraram tudo em um único chip. Menor e mais simples, a placa-mãe traz apenas as conexões essenciais: duas entradas USB, duas saídas de vídeo (uma HDMl e outra RCA), porta para conexão de rede, um leitor de cartão e fonte. O carregador é igual ao de um celular.

A placa conquistou os inventores e começou a ser incluída nos projetos mais diversos, como gerenciamento de mídia e criação de música. 0 entusiasta Dave Akerman mandou o Raspberry Pi para o espaço em busca de belas imagens, que eram transmitidas ao vivo pelo minicomputador.

Mas o Raspberry Pi não é apenas um instrumento para dar asas à imaginação. Alguns empreendedores querem usá-lo para lucrar com produtos feitos a partir dele. Não é necessário pedir nenhuma autorização especial ou licença. A única exigência é que, no pacote, o fabricante inclua o nome da placa e, se as vendas forem um sucesso, os desenvolvedores considerem doar uma pequena parte dos lucros à fundação de Cambridge.

Quem não é profissional, pode usar a ferramenta da mesma forma. O Raspberry PI traz dois softwares de programação: o Scratch, para alunos de 6 a 8 anos, e o Python, para quem já chegou a um nível mais avançado."

2Percebemos um movimento no sentido de recriar o trabalho no campo da informática educacional, no

\footnotetext{
${ }^{2}$ http://g1.globo.com/globo-news/noticia/2012/10/cientistas-criam-computador-para-ensinar-programacaocriancas.html
} 


\section{Programação de computadores para melhoria da aprendizagem}

sentido de aproveitar a potencialidade de criação dos alunos e não somente reproduzir jogos dos softwares existentes.

Seguindo esse raciocínio, pensamos em desenvolver aulas mais voltadas para a programação de computadores, não precisaríamos adquirir esse chip específico, apenas aproveitar alguns softwares existentes para trabalhar a programação.

O principal estaria sendo trabalhado, que é o desenvolvimento da criatividade e o trabalho com o raciocínio lógico.

O trabalho de divulgação do projeto envolve a comunicação com a família e os alunos, explicando a finalidade e mostrando programações que podem ser feitas.

A realização de murais na escola envolvendo exemplos de programas que podem ser criados é o início da divulgação, da campanha de marketing, depois faremos as exposições dos programas criados pelos próprios alunos.

Para conseguirmos verba para o projeto, mostraremos aos dirigentes, as vantagens de se trabalhar com programação, as habilidades que podem ser desenvolvidas nos alunos e os exemplos que temos no mundo, mostrando a necessidade de acompanhar a evolução tecnológica, formando sujeitos preparados para criar soluções nas diferentes situações presentes no dia a dia.

\section{Organização e gerência do empreendimento}

A equipe de docentes da escola é composta por muitos professores jovens, com disposição e abertura para novas idéias, estão antenados com a tecnologia da informação, encontramos um campo fértil para a implantação do projeto.

Temos uma Analista de Suporte em Informática bem afinada com os trabalhos desenvolvidos pelos professores,com muita experiência em informática. O estagiário da informática também é muito envolvido com o trabalho, é conhecedor de programas de computador e possui experiência no assunto.

Os alunos gostam de desafios, de aplicar conhecimentos, de descobrir,criar,serem úteis.Acreditamos que 0 trabalho com programação é desafiadora e instigante para a natureza curiosa dos alunos.

A operacionalização do projeto envolve o trabalho do Analista de Informática, estagiário e professores de todas as áreas de conhecimento, coordenadores, administrador escolar e secretaria escolar.

Primeiramente haverá uma formação para os professores explicando o funcionamento da programação, sua aplicação nas áreas de conhecimento, os softwares disponíveis, as possibilidades de desenvolvimento de habilidades e competências nos alunos e todas as outras funcionalidades que a programação permite.

Num segundo momento é hora dos professores escolherem uma situação problema para solucionar a partir do uso da programação. Os professores precisam entender que não há um único caminho a ser percorrido pelo aluno, é um campo vasto para aplicar a criatividade e o conhecimento. É um jogo de erros e acertos, de idas e vindas, de pesquisas e estudo para concluir a programação.

Ao escolherem a situação problema, o professor deverá entrar em contato com o Analista de Suporte em informática para pedir orientação de qual software é combatível com o problema a ser solucionado.Caso o software necessário não esteja disponível na escola e não seja possível baixá-lo, a Analista de suporte em informática deverá solicitá-lo à Direção para providenciar a compra.

Toda a atividade de programação deverá ser desenvolvida no laboratório de informática na parceria professor/ analista de suporte em informática.

Suporte e estrutura para a operacionalização do projeto ficará por conta do administrador, coordenador e secretaria. A apresentação do projeto, o planejamento e orçamento previsto, a contratação de especialista em programação para formação dos professores, a disponibilização de computadores e compra de softwares ficará a cargo da direção com apoio da secretaria. 


\section{Adriana Moralles}

O acompanhamento do trabalho realizado pelos professores com os alunos será feito pelo coordenador pedagógico, que avaliará e orientará os professores no desenvolvimento do projeto.

0 projeto terá a validade de 12 meses inicialmente, podendo ser prorrogado por tempo indeterminado conforme aceitação e resultados que serão analisados em avaliações externas, avaliações internas e em atitudes dos alunos.

Anualmente pretendemos montar uma feira da tecnologia, convidando alunos de outras escolas para a feira, onde os alunos da nossa escola apresentarão as programações desenvolvidas ao longo do ano.

\section{Plano financeiro}

Investimento (despesas de capital)

\begin{tabular}{|c|c|c|c|}
\hline \multicolumn{4}{|c|}{ Investimentos (despesas de capital) } \\
\hline Item & Ano1 & Ano2 & Ano3 \\
\hline Obras e infraestrutura & $1.500,00$ & 0,00 & 0,00 \\
\hline Instalações & $1.500,00$ & & \\
\hline Material permanente & $6.596,00$ & 0,00 & 0,00 \\
\hline Softwares & $1.104,00$ & & \\
\hline Computadores & $5.492,00$ & & \\
\hline Total & $8.096,00$ & 0,00 & 0,00 \\
\hline
\end{tabular}

\section{Detalhamento}

Softwares- 8 kits arduino ( $\$ 138,00$ cada kit)

Computadores: 4 computadores para reposição PC Positivo Intel Celeron 847,2 GB, HD 3206 B, SIM, D 2880- Linux+ Monitor LED 23 "Philips" ( FULL HD)- 236V4LSB( R\$1.373,00 cada)

Instalações dos computadores: mão de obra e materiais 


\section{Programação de computadores para melhoria da aprendizagem}

\section{Despesas correntes}

\begin{tabular}{|llll|}
\hline $\begin{array}{l}\text { Projeção de despesas correntes } \\
\text { Material de consumo }\end{array}$ & Total ano 1 & Total ano 2 & Total ano 3 \\
papel sulfite A4 & & & \\
Total & $1.554,00$ & $1.662,78$ & 1.779 .17 \\
& & & \\
Serviços de Terceiros & Total ano 1 & Total ano 2 & Total ano 3 \\
manutenção de equipamentos & $3.600,00$ & $3.600,00$ & $3.600,00$ \\
Total & $3,600,00$ & $3.600,00$ & $3.600,00$ \\
Total de despesas correntes & $5.154,00$ & $5.262,78$ & 5.379 .17 \\
\hline
\end{tabular}

\section{Detalhamento}

Papel Sulfite A4 - 20 resmas por mês (equivalente a uma resma por turma)

Manutenção de equipamentos - Gasto de manutenção por mês $\mathrm{R} \$ 3.600,00$

\begin{tabular}{lcccc}
\hline Projeção de despesas correntes & Total ano 1 & Total ano 2 & Total ano 3 \\
Material de consumo & & & \\
papel sulfite A4 & & & \\
Total & $1.554,00$ & $1.662,78$ & 1.779 .17 \\
Serviços de Terceiros & Total ano 1 & Total ano 2 & Total ano 3 \\
manutenção de equipamentos & $3.600,00$ & $3.600,00$ & $3.600,00$ \\
Total & $3,600,00$ & $3.600,00$ & $3.600,00$ \\
Total de despesas correntes & $5.154,00$ & $5.262,78$ & 5.379 .17
\end{tabular}




\section{Despesas administrativas e de pessoal}

\begin{tabular}{|lccc|}
\hline $\begin{array}{l}\text { Projeção das Despesas Administrativas e de } \\
\text { Pessoal }\end{array}$ & Ano 1 & Ano 2 & Ano 3 \\
Administrativas & & & \\
Água & $1.560,00$ & $1.638,00$ & $1.719,90$ \\
Energia Elétrica & $3.240,00$ & $3.434,40$ & $3.640,46$ \\
Telefone & $2.640,00$ & 2798,4 & $2.966,30$ \\
Total & $7.440,00$ & $7.840,01$ & $8.326,66$ \\
& & & \\
Pessoal & Ano 1 & Ano 2 & Ano 3 \\
Secretário & $1.560,00$ & $1.560,00$ & $1.560,00$ \\
Analista de Suporte em Informática & $11.760,00$ & $11.760,00$ & $11.760,00$ \\
Total & $13.320,00$ & $13.320,00$ & $13.320,00$ \\
Total das despesas correntes & $20.760,00$ & $21.190,80$ & $21.646,66$ \\
\hline
\end{tabular}

\section{Necessidade de recursos}

\begin{tabular}{|c|c|c|c|c|}
\hline \multicolumn{4}{|l|}{ Cálculo da Necessidade de Recursos } & \multirow[b]{2}{*}{ TOTAL } \\
\hline Item & ANO 1 & ANO 2 & ANO 3 & \\
\hline I. Total das Despesas Correntes & $5.154,00$ & $5.262,78$ & $5.379,17$ & $15.795,95$ \\
\hline Material de Consumo & $1.554,00$ & $1.662,78$ & $1.779,17$ & $4.995,95$ \\
\hline Passagens e Despesas com Locomoção & 0,00 & 0,00 & 0,00 & 0,00 \\
\hline Serviços de Terceiros & $3.600,00$ & $3.600,00$ & $3.600,00$ & $10.800,00$ \\
\hline II. Total de Despesas Administrativas & $7.440,00$ & $7.870,80$ & $8.326,67$ & $23.637,47$ \\
\hline III. Total de Despesas com Pessoal & $13.320,00$ & $13.320,00$ & $13.320,00$ & $39.960,00$ \\
\hline IV. Total de Despesas de Capital (investimentos) & $8.096,00$ & 0,00 & 0,00 & $8.096,00$ \\
\hline Necessidade de Recursos (I+|I+|II+IV) & $34.010,00$ & $26.453,58$ & $27.025,84$ & $87.489,42$ \\
\hline Recursos Edital & $13.250,00$ & $5.262,78$ & $5.379,17$ & $23.891,95$ \\
\hline Recursos da Organização (contrapartida) & $20.760,00$ & $21.190,80$ & $21.646,67$ & $63.597,47$ \\
\hline
\end{tabular}




\section{Programação de computadores para melhoria da aprendizagem}

\section{Validações}

\begin{tabular}{|lc|}
\hline $\begin{array}{l}\text { Despesas Correntes } \\
\text { Despesas de Capital }\end{array} \quad 8.096,00$ & $66.12 \%$ \\
$\begin{array}{l}\text { (máximo de } 50 \% \text { do } \\
\text { projeto) }\end{array}$ & $33,88 \%$ \\
$\begin{array}{l}\text { Total de Recursos } 23.891,95 \\
\text { Solicitados }\end{array}$ & $100 \%$ \\
Contrapartida & \\
Valor total da contrapartida & $\mathbf{6 3 . 5 9 7 , 4 7}$ \\
$\begin{array}{l}\text { Valor solicitado ao edital pelo } \mathbf{2 3 . 8 9 1 , 4 7} \\
\text { projeto }\end{array}$ \\
Percentual: contrapartida / recursos solicitados : $\mathbf{2 6 6 \%}$ \\
\hline
\end{tabular}

